\title{
Environmental controls of wood entrapment in upper Midwestern streams
}

\author{
Eric Christopher Merten, ${ }^{1 *}$ Jacques Finlay, ${ }^{2}$ Lucinda Johnson, ${ }^{3}$ Raymond Newman, ${ }^{1}$ \\ Heinz Stefan ${ }^{4}$ and Bruce Vondracek ${ }^{5 \dagger}$ \\ ${ }^{1}$ Department of Fisheries, Wildlife and Conservation Biology, University of Minnesota, 1980 Folwell Avenue, St. Paul, MN 55108, USA \\ ${ }^{2}$ Department of Ecology, Evolution, and Behavior, University of Minnesota, 1987 Upper Buford Circle, St. Paul, MN 55108, USA \\ ${ }^{3}$ Natural Resources Research Institute, University of Minnesota - Duluth, 5013 Miller Trunk Highway, Duluth, MN 55811, USA \\ ${ }^{4}$ Department of Civil Engineering, University of Minnesota, 23rd Avenue, SE, Minneapolis, MN 55455, USA \\ ${ }^{5}$ U.S. Geological Survey, Minnesota Cooperative Fish and Wildlife Research Unit, University of Minnesota, 1980 Folwell Avenue, St. Paul, MN, \\ 55108, USA
}

\begin{abstract}
:
Wood deposited in streams provides a wide variety of ecosystem functions, including enhancing habitat for key species in stream food webs, increasing geomorphic and hydraulic heterogeneity and retaining organic matter. Given the strong role that wood plays in streams, factors that influence wood inputs, retention and transport are critical to stream ecology. Wood entrapment, the process of wood coming to rest after being swept downstream at least $10 \mathrm{~m}$, is poorly understood, yet important for predicting stream function and success of restoration efforts. Data on entrapment were collected for a wide range of natural wood pieces $(n=344)$, stream geomorphology and hydraulic conditions in nine streams along the north shore of Lake Superior in Minnesota. Locations of pieces were determined in summer 2007 and again following an overbank stormflow event in fall 2007. The ratio of piece length to effective stream width (length ratio) and the weight of the piece were important in a multiple logistic regression model that explained $25 \%$ of the variance in wood entrapment. Entrapment remains difficult to predict in natural streams, and often may simply occur wherever wood pieces are located when high water recedes. However, this study can inform stream modifications to discourage entrapment at road crossings or other infrastructure by applying the model formula to estimate the effective width required to pass particular wood pieces. Conversely, these results could also be used to determine conditions (e.g. pre-existing large, stable pieces) that encourage entrapment where wood is valued for ecological functions. Copyright $(C) 2010$ John Wiley \& Sons, Ltd.
\end{abstract}

KEY WORDS wood movement; wood entrapment; wood transport

Received 18 December 2009; Accepted 20 July 2010

\section{INTRODUCTION AND BACKGROUND}

Wood pieces deposited in streams provide a wide variety of ecosystem functions. Foremost, wood enhances habitat conditions for key species in stream food webs, including invertebrates and fish (Angermeier and Karr, 1984; Berg et al., 1998; Johnson et al., 2003; Eggert and Wallace, 2007). Wood also increases hydraulic heterogeneity and transient storage, promotes hyporheic recharge, encourages pool formation and channel meandering, and retains leaves and other organic matter (Beechie and Sibley, 1997; Mutz and Rohde, 2003; Mao et al., 2008; Stofleth et al., 2008). The frequency and size of wood inputs vary in space and time (Golladay et al., 2007; Latterell and Naiman, 2007) and are strongly affected by riparian management (Flebbe and Dolloff, 1995; Kreutzweiser et al., 2005; Czarnomski et al., 2008). The importance of wood for stream function is increasingly recognized (Gregory et al., 2003), particularly as the adverse effects of historic

* Correspondence to: Eric Christopher Merten, Department of Fisheries, Wildlife and Conservation Biology, University of Minnesota, 1980 Folwell Avenue, St. Paul, MN 55108, USA. E-mail: mert0042@umn.edu $\dagger$ The contribution of Bruce Vondracek to this article was prepared as part of his official duties as a United States Federal Government employee. 'woody debris' removal become more evident (Walter and Merritts, 2008).

Given the strong role that wood plays in stream ecosystems, understanding the factors that influence wood transport is critical to stream ecology and restoration. One aspect of wood transport that is poorly understood is wood entrapment, the process by which moving wood pieces in a stream come to rest after travelling downstream. Thus, predicting the dynamics of wood entrapment can be valuable for maintaining or changing the ecological function of natural streams, and for restoring systems that have been degraded due to channel simplification, erosion and other human-driven changes.

Direct observation of individual pieces of wood is the optimal method for studying wood entrapment. Other field methods rely on the examination of wood standing stocks and assume that wood recruitment is spatially homogeneous, which is unlikely to be true (Latterell and Naiman, 2007). Studies assessing the movement of individual pieces of wood date to at least (Bilby, 1984), who concluded that piece length was the primary factor in determining the distance travelled before entrapment. Subsequent field studies identified length ratios (i.e. the ratio of piece length to stream width) as important in 
determining wood entrapment over a range of conditions, as reviewed by Gurnell et al. (2002) and Hassan et al. (2005). For example, Lienkaemper and Swanson (1987) determined that the primary factor for entrapment was the ratio of the piece length to the channel width. Although the largest empirical study to date ( $n=2105$ pieces) found little correlation between piece length and distance travelled $\left(r^{2}=0 \cdot 11\right.$, Jacobsen et al. (1999)), the lack of correlation was likely due to the use of pieces much shorter than the width of the large river studied (Gurnell et al., 2002; Hassan et al., 2005).

Although field studies of entrapment characterize pieces of wood in terms of mean length and mean diameter, there are other attributes which may be important but were not considered in previous models. For example, wood pieces with more branches and twigs have greater branching complexity (Newbrey et al., 2005) which may increase entrapment rates due to entanglement of branches in rocks or bank vegetation. Momentum and draft may also influence whether a piece can overcome resistance from the stream bed or obstructions (Braudrick and Grant, 2001).

Two laboratory studies used dowels in flumes to examine wood entrapment in greater detail under simplified conditions. Braudrick and Grant (2001) examined the influence of piece length and diameter relative to channel width, depth and sinuosity. Although little correlation was found with dowel entrapment, the detailed measurements set a new standard for examinations of entrapment. Using a similar approach with dowels in a flume, Bocchiola et al. (2006) developed robust predictions of entrapment by floating dowels through a gauntlet of obstructions. However, it remains unclear how well the results from flume studies can predict entrapment under the heterogeneous conditions found in natural streams.

Haga et al. (2002) provided a starting point for integrating the detailed mechanistic approach of flume studies with the realism of a field study. A $5 \cdot 5-\mathrm{km}$ reach was divided into 24 segments, and mean water depth during peak discharges was estimated for each segment. A total of 63 tagged pieces were placed in the stream channel and tracked over a 13-month period; entrapment generally followed hydraulic predictions related to the ratio of piece diameter to water depth (Haga et al., 2002). However, it is unclear whether their results are representative of natural conditions, as all pieces studied were cut to similar length, were shorter than the bankfull width, had branches removed and were similar in density.

Overall, studies of wood entrapment to date leave a number of questions unanswered. Can the probability of entrapment be predicted for a given ratio of piece length to channel width? Does the ratio of piece diameter to water depth proposed by Haga et al. (2002) predict entrapment over a natural range of wood piece characteristics? Does branching complexity or rootwad presence play a role in entrapment? The resolution of previous field measurements may have overlooked important mechanisms, whereas results from studies with dowels or flumes may not apply to natural wood in natural streams.
Our objective in this paper is to predict and test the mechanisms controlling wood entrapment, using a natural range of characteristics for wood pieces, stream geomorphology and hydraulic conditions. We first outline the mechanisms involved with wood entrapment to develop a theoretical basis for entrapment in streams. We then describe how we integrated detailed measurements, usually made only in flume studies, with field measurements in nine natural streams. Finally, we present and interpret results from empirical analysis of our extensive dataset for wood entrapment.

\section{MECHANISMS FOR ENTRAPMENT}

A piece of wood travelling downstream may be entrapped in a variety of ways. For example, the piece may come into contact with the stream bed and be stopped by friction, or become lodged against an obstruction, such as a boulder. Factors that can cause wood to be entrapped are described below.

\section{Hydrology and hydraulics}

Pieces of wood are most likely to be mobilized and entrained during peak discharge (Bilby, 1984; Wohl and Goode, 2008), when unit stream power, water levels and velocities in the channel are highest. Unit stream power $(\omega)$ is defined as

$$
\omega=\rho_{\mathrm{w}} g R U \alpha
$$

where $\rho_{\mathrm{w}}$ is the density of water, $g$ is the gravity, $R$ is the hydraulic radius for the channel (approximated by the water depth in a wide stream), $U$ is the stream velocity and $\alpha$ is the stream slope (Gordon et al., 2004). Under uniform flow conditions, the water level and mean velocity for a channel cross-section can be related by Manning's equation, which is a function of the discharge rate, wetted cross-sectional area and the channel roughness coefficient (Gordon et al., 2004). Channel roughness, in turn, is a function of the channel's shape, substrate and vegetation (Arcement and Schneider, 1989). Channel roughness is also influenced by obstructions, such as rocks, boulders and stationary wood pieces, which can have more direct effects on entrapment.

\section{Interactions with the stream bed}

In the simplest case, we consider an individual piece of wood travelling down a wide stream, under conditions where interaction with the stream bed is the only mechanism for entrapment. If no obstructions (e.g. rocks, boulders or stationary wood pieces) are present, the piece may stop when it encounters a shallow stream reach and contacts the stream bed. If the shallow area is extensive, friction may reduce or stop the forward momentum of the piece and cause the wood to be entrapped. The momentum $(M)$ of a wood piece is defined as

$$
M=m U
$$


where $m$ is the mass of the piece (i.e. density multiplied by volume). Piece velocity $(U)$ is approximately equal to water velocity for a floating piece that is not in contact with the stream channel (Braudrick and Grant, 2001).

The draft $(D)$ is the primary variable that controls the level to which a wood piece will contact the stream bed. Draft refers to the submerged depth of a floating piece, and can be estimated from Braudrick et al. (1997) from piece radius and density as

$$
D=2 r\left(0.05+0 \cdot 9\left(\rho_{\log } / \rho_{\mathrm{w}}\right)\right)
$$

where $r$ is the radius of the piece and $\rho_{\log }$ is the density of the piece. A piece contacts the stream bed when the draft exceeds the water depth; the ratio of the piece draft to the water depth (draft ratio) is therefore an indicator of entrapment potential. Water depth is variable in natural streams (Gordon et al., 2004) even when obstructions are not present; overall conditions can be summarized using the mean depth in the channel.

Blockage may also affect the probability that a wood piece will make contact with the stream bed or banks; blockage is the proportion of the wetted area occupied by the piece. Blockage is heavily influenced by the orientation of the piece; blockage is least for pieces oriented parallel to the direction of flow and greatest for those oriented perpendicular to the flow. Pieces tend to orient themselves parallel to flow once mobilized (Braudrick and Grant, 2001). The orientation of a piece also affects the probability that it will encounter shallow areas; a piece oriented perpendicular to the direction of flow is more likely to encounter shallow areas than a piece oriented parallel to the flow (although perpendicular pieces may also move by rolling).

\section{Interactions with obstructions in the stream channel}

In natural streams, stationary obstructions are often present, such as large boulders, islands and other pieces of wood. The process of entrapment by obstructions is determined by several contingencies. First, a piece must encounter an obstruction. The probability of encounter is a function of the density of obstructions present (Bocchiola et al., 2006), the draft of the piece relative to the elevation of the obstruction and the orientation of the piece. Second, the obstruction must be sufficiently anchored to resist the forces exerted by the impact of a moving wood piece. If the obstruction is a smaller piece of wood, for example, it may become dislodged and the original piece may escape entrapment. Third, the piece must not pivot off the obstruction. The moment forces that determine whether a piece will pivot are a function of the location along the piece that encounters the obstruction; pieces that contact an obstruction at their midsection are less likely to pivot than pieces that encounter an obstruction near either end.

A wood piece may also encounter a group of obstructions. If a piece becomes at once braced against multiple obstructions, the chance of dislodging the obstructions is diminished. For example, the aggregate resisting force exerted by several small rocks may be sufficient to entrap a large floating piece, even if the piece would have dislodged any one of the rocks in isolation. A group of obstructions may also reduce the probability that a piece will pivot and continue downstream; a piece that bridges multiple obstructions affords less hydraulic leverage.

\section{Interactions with stream banks and vegetation}

Stream banks can entrap pieces of wood via two mechanisms. First, long pieces may become wedged across the stream channel. The primary factor in determining the distance a piece travels is the ratio of the piece length to the bankfull channel width (Lienkaemper and Swanson, 1987; Gurnell et al., 2002; Hassan et al., 2005). We define a ratio of piece length to stream width as a length ratio. Second, a wood piece may become entrapped against the stream banks in sinuous streams. Braudrick and Grant (2001) predicted that pieces would become entrapped on the outside of meander bends, as measured by the radius of curvature for the stream. The forward momentum of a piece may carry it against the outside bank when the meander bend has a small radius of curvature, providing an opportunity for the piece to be entrapped by the bank.

Bank vegetation can also be important to entrapment (Jacobsen et al., 1999; Millington and Sear, 2007; Opperman and Merenlender, 2007). During high discharge, pieces may become entangled in live vegetation and held fast if the vegetation has sufficient structural strength. Riparian vegetation can thus reduce the wetted stream width that is effectively available to transport wood.

\section{Predictors for wood entrapment}

On the basis of the preceding discussion, we assembled seven variables as potential predictors for the entrapment of wood pieces in natural streams. We considered six variables as likely to affect the probability that a piece would contact the stream bed, banks or other obstructions: piece weight, draft ratio, length ratio, branching complexity, rootwad presence and blockage. We also considered momentum as likely to affect the probability that a piece is pushed past an obstruction after an encounter. Previous studies have shown length ratio or draft ratio as important and have either not detected or not examined a contribution from weight, branching complexity, rootwad presence, blockage and momentum. To test the relation of our seven variables to entrapment, we designed a field study in northern Minnesota that encompassed a wide range of conditions found in temperate forested streams.

\section{FIELD DATA COLLECTION}

\section{Study design}

We examined the mechanisms of wood entrapment in nine streams of second- and third-growth forested watersheds along Lake Superior in Minnesota (Figure 1). 


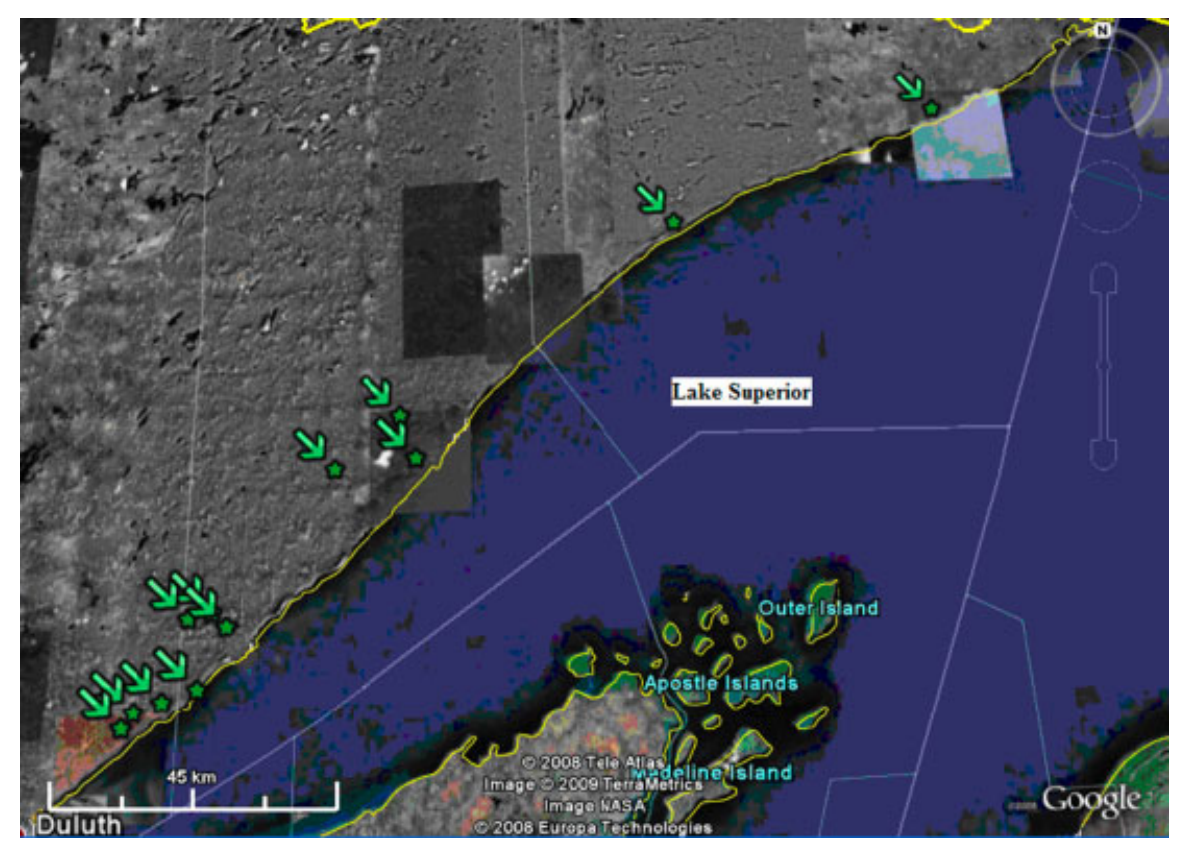

Figure 1. Study sites (stars with arrows) along the north shore of Lake Superior in Minnesota. The three northernmost sites were not sampled in fall 2007. Duluth, Minnesota, is in the southwest corner and the Canadian border is in the northeast corner

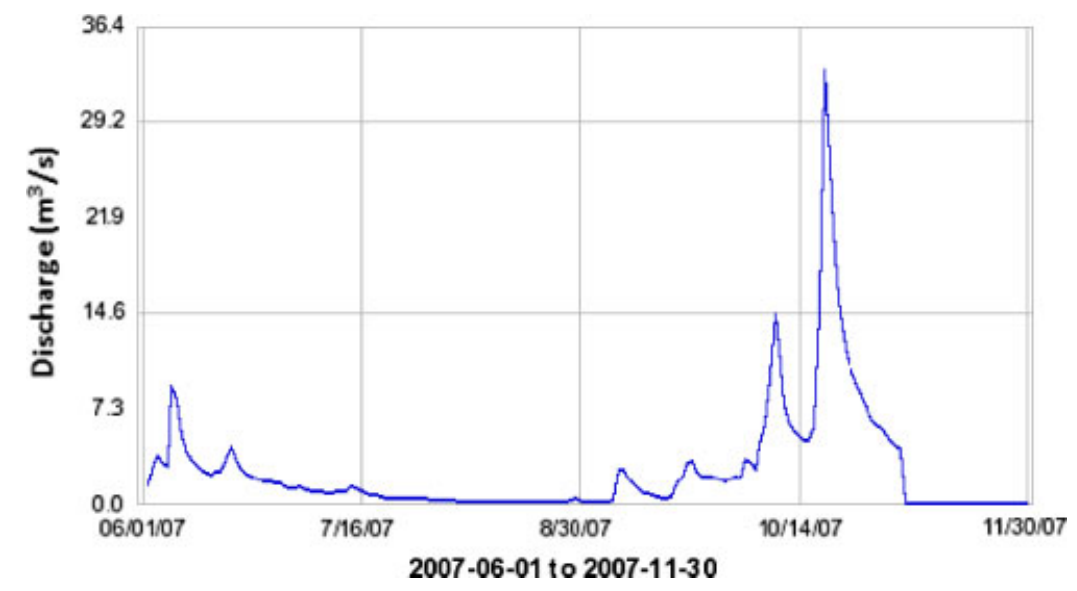

Figure 2. Hydrograph for the Poplar River during the study period from June to November 2007. Hydrographs at other study streams were similar. Data from Minnesota Pollution Control Agency

Standing stocks of large wood in the area average $0 \cdot 20$ pieces $/ \mathrm{m}$, which is lower than most published values worldwide (Merten and Decker-Fritz, 2010). The streams had continuous discharge data available; a study reach was established in each stream near the discharge gauge. The study reach at each stream was 250-800 $\mathrm{m}$ in length (4190 $\mathrm{m}$ total) and was divided into $10-\mathrm{m}$ sections (marked with wire flags, flagging tape and GPS) as the basis for piece locations and geomorphic conditions. Stream beds were dominated by cobble and gravel (Merten, 2009), and mean bankfull widths of the nine study reaches ranged from 3.4 to $24.4 \mathrm{~m}$.

Water levels in summer 2007 were low (Figure 2) due to extreme drought conditions (USDA Drought Monitor, 14 August 2007). However, storms from midSeptember through mid-October produced heavy rainfall in the study area; rainfall observers within $10 \mathrm{~km}$ of Lake Superior from Duluth to Silver Bay recorded an average of $25.3 \mathrm{~cm}$ of rainfall $(s . d .=2.3)$ from 15 September 2007 to 15 October 2007, compared to $19.6 \mathrm{~cm}$ for the entire period from 15 June 2007 to 15 September 2007 (Minnesota State Climatology Office). The rainfall caused a stormflow with a recurrence interval of 1.1 years at the Knife River, the only study stream with a long-term hydrologic record (per the St. Louis County Soil and Water Conservation District). Although the hydrologic records were insufficient to estimate the recurrence intervals at other study streams, the relatively even rainfall throughout the study area suggests that the recurrence intervals at other study streams were comparable to the Knife River. Spate flows are common in streams in the region (Detenbeck et al., 2005), and overbank discharges were observed at all nine study streams during the stormflow event. 
Table I. Variables measured or calculated (see text for details)

\begin{tabular}{ll}
\hline Measured by piece & \multicolumn{1}{c}{ Measured by 10-m section } \\
\hline Total length & $\begin{array}{l}\text { Cross-sectional elevations } \\
\text { Stream gradient (slope) }\end{array}$ \\
$\begin{array}{l}\text { Diameter }(2 r) \\
\text { Bood density }\left(\rho_{\mathrm{log}}\right)\end{array}$ & Effective stream width \\
Branching complexity & \\
Rootwad presence & \\
\hline Calculated by piece & Calculated by 10-m section \\
\hline Volume $\left(V_{\log }\right)$ & Mean velocity in channel $(U)$ \\
Weight & Mean channel depth \\
Draft $(D)$ & Unit stream power in channel $(\omega)$ \\
Length ratio $\left(L^{*}\right)$ & Wetted area in channel \\
Draft ratio $\left(D^{*}\right)$ & - \\
Momentum $(M)$ & \\
Blockage & \\
\hline
\end{tabular}

\section{Wood data}

In June through August of 2007, all pre-existing large wood pieces $(>0.1 \mathrm{~m}$ in diameter for a portion $>1 \mathrm{~m}$ in length) in the study reaches were located and marked. A subset $(n \approx 20)$ of smaller pieces $(>0.05 \mathrm{~m}$ in diameter for a portion $>1 \mathrm{~m}$ in length) were also located and marked in each study reach, for a total of 956 pieces. Pieces were included if they were entirely dead but still rooted, or still alive but entirely uprooted. Measurements were taken on each piece as described below to obtain the parameters listed in Table I. All pieces that lay within the channel or that had a portion $>0.05 \mathrm{~m}$ in diameter extending into the bankfull channel were included. Each piece was marked twice with flagging tape and one ( $n=334)$ or three $(n=622)$ individually numbered tags. Total length (for the portion $>0.01 \mathrm{~m}$ in diameter) and mean diameter were measured using tree callipers at both ends and the middle of each piece. Rootwads were noted if present. All marked pieces in the study areas were located again in mid-October through November 2007, after floodwaters had receded, including pieces that had been ejected onto the floodplain. Branching complexity was assessed for each piece following Newbrey et al. (2005), and the density was determined using a sample obtained with an increment borer. Weight of each piece was estimated as the product of volume and density, and draft of each piece was estimated using the density and mean radius per Equation (3).

A new cohort of pieces was used to examine entrapment mechanisms in 2008. All new (i.e. unmarked) pieces that were $>0.1 \mathrm{~m}$ in diameter for a portion $>1 \mathrm{~m}$ in length were located in June through August 2008 in each study reach. Study reaches on three additional streams were sampled where all pieces had been marked in summer 2007 but not revisited in fall 2007, while one reach sampled in fall 2007 was not revisited in summer 2008. Pieces that were clearly recruited locally from riparian trees within the study reach ( $n=22$ freshly fallen trees) were excluded in 2008; all other new pieces $(n=178)$ were assumed to have moved from upstream of the reach. The method of entrapment was noted for each new piece using the following categories: lying loose in the channel, braced by rocks, braced by other pieces of wood, braced by the stream banks or bed, braced by live trees but with the center of the piece remaining within $1 \mathrm{~m}$ of the bankfull channel or ejected onto the floodplain with the center $>1 \mathrm{~m}$ outside the bankfull channel. The 2008 data were thus used to characterize the most common mechanisms for entrapment.

\section{Stream geomorphic data}

Data on stream geomorphology were collected from all study reaches in summer 2007. Cross-sections were surveyed every $10 \mathrm{~m}$ in each study reach using a measuring tape and a laser level on a tripod (Harrelson et al., 1994), except at the two largest streams where 40 of 80 (Beaver River) or 12 of 50 (Knife River) 10-m sections were surveyed. The bed slope was calculated for each reach using the difference in elevation between the lowermost points at the upstream and downstream ends of the reach. The effective stream width was estimated for each 10-m section as the shortest unobstructed width for flows $0.5 \mathrm{~m}$ above bankfull (Figure 3). Vegetation was considered to be obstructive if the stem diameter was at least $0.02 \mathrm{~m}$. Initial estimates of Manning's roughness coefficient for the channel and the floodplain were made using the methods of Arcement and Schneider (1989).

\section{Hydraulic data}

The computer simulation model HEC-RAS 4.0 (available online) (http://www.hec.usace.army.mil/software/ hec-ras/) was used to calculate hydraulic parameters for each 10-m section; HEC-RAS is appropriate for studying stream characteristics at the 10-m resolution (Brooks et al., 2006). On the basis of geomorphic survey data, HEC-RAS was used to estimate unit stream power, stage, velocity and energy grade slope (Gordon et al., 2004) at each 10-m section for discharges corresponding to the peak flow during overbank conditions in fall 2007. Although overbank flows were included in the models and used for wetted width, only the portion of the discharge that was in the bankfull channel was considered when calculating mean velocity, depth, unit stream power and wetted area (Table I).

To calibrate the hydraulic model for each study reach, the initial estimate for Manning's channel roughness coefficient was varied (between 0.02 and 0.07) to obtain

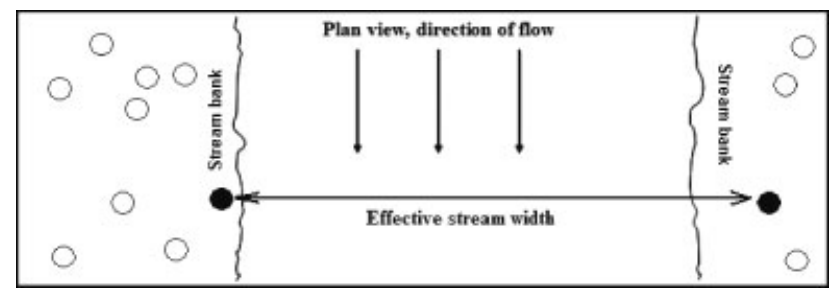

Figure 3. Plan view of channel illustrating lateral positions of trees (open circles) large enough to brace a floating piece of wood. Effective stream width was defined as the lateral distance between the innermost trees (closed circles) for each 10-m section of stream or the actual wetted width, whichever was shorter 
the best fit between the predicted and observed stream stage as measured at each cross-section during summer 2007. The final $r^{2}$ values between the predicted and observed stream stages ranged from 0.77 to 1.00 .

\section{Wood entrapment}

In fall 2007, after floodwaters had receded, we located tagged wood pieces in each study reach. Pieces that travelled downstream at least $10 \mathrm{~m}$ were used; we considered $10 \mathrm{~m}$ as the minimum distance for avoiding 'false positives' (where measurement error in the field made it appear that a stationary piece had moved) and allowing pieces in motion to equilibrate with the water velocity (Braudrick and Grant, 2001). Pieces that did not move or that moved less than $10 \mathrm{~m}$ were not classified as mobilized and were thus culled from the dataset. The dataset of pieces that moved at least $10 \mathrm{~m}$ was split into two groups: those that left the study reach and were not found and those that travelled downstream but were entrapped before leaving the study reach. We used a logistic response for subsequent analyses of entrapment; pieces in the former group were assigned a 0 and pieces in the latter group were assigned a 1 . Although pieces were not re-measured, only seven mobilized pieces were known to have broken (based on the position of the tags; the shorter portion of the piece was disregarded). For each piece that left the study reach, we recorded the specific 10-m sections the piece passed through, and associated the mean geomorphic and hydraulic data of those sections with that piece. For each piece that moved but was entrapped within the study reach, we used the geomorphic and hydraulic data of the section in which the piece was entrapped.

\section{DATA ANALYSIS METHODS}

Data from wood pieces, stream geomorphology and hydraulic simulations were used to quantify predictor variables considered likely to influence wood entrapment. The length ratio was piece length divided by effective stream width, and the draft ratio was piece draft divided by mean depth in the channel. Blockage was calculated as the submerged area (assuming the piece was oriented parallel to flow as suggested by Braudrick and Grant (2001)) divided by the wetted channel area. Weight of each piece was its volume multiplied by density, and momentum of each piece was calculated using Equation (2) assuming that the piece travelled at the same velocity as the flow (Braudrick and Grant, 2001).

A multiple logistic regression model was developed to determine the factors most important to wood entrapment, using the logistic entrapment data as the response variable. The predictor variables for the initial model were length ratio, weight, draft ratio, branching complexity, rootwad presence, blockage and momentum. The final model was chosen using the statistical software R (available online) (http://www.r-project.org/) to examine the best fit between possible combinations of predictor variables and the logistic response variable. The final model had the lowest Akaike information criterion (AIC) among all models; in other words, the model contained the fewest possible number of meaningful predictors (Burnham and Anderson, 1998). The Variance inflation factor (VIF) was used as a further screen for the variables; variables with VIF $>2$ were collinear (i.e. not independent from one another) and excluded from the final model. The regression equation for the final model produced a probability of entrapment for a given piece passing through a given $10-\mathrm{m}$ section.

\section{RESULTS}

A total of 956 pieces of wood were tagged and measured, but most were excluded from analyses for several reasons. First, pieces $(n=98)$ were excluded if they were initially part of a spanning logjam. These pieces would be expected to exhibit congested flow, where all pieces in the logjam would travel downstream en masse rather than independently from one another (Braudrick et al., 1997). Two spanning logjams were initially present; both were completely mobilized by the high discharge in fall 2007 and likely did not influence entrapment of other pieces. Second, an additional 12 pieces were excluded because they became entrapped by a culvert at the downstream end of a study reach. Entrapment by culverts was only observed at one of the study reaches, where two 6-m culverts had been placed side by side for a road crossing. Third, pieces $(n=502)$ were excluded if they travelled less than $10 \mathrm{~m}$ between summer and late fall 2007. Thus, there were a total of 344 wood pieces for the analysis of entrapment.

Wood pieces and streams covered a range of characteristics (Table II). For example, the mean piece length was $2.8 \mathrm{~m}$ with a standard deviation (s.d.) of $2.1 \mathrm{~m}$, mean

Table II. Mean and standard deviation for characteristics of wood pieces and $10-\mathrm{m}$ stream sections at the nine study reaches

\begin{tabular}{lccc}
\hline & Units & Mean & \\
\hline Piece length & $\mathrm{m}$ & $2 \cdot 8$ & $2 \cdot 1$ \\
Length ratio & - & $0 \cdot 31$ & $0 \cdot 36$ \\
Diameter $(2 r)$ & $\mathrm{m}$ & $0 \cdot 15$ & $0 \cdot 13$ \\
Wood density $\left(\rho_{\text {log }}\right)$ & $\mathrm{g} / \mathrm{cm}^{3}$ & $0 \cdot 74$ & $0 \cdot 33$ \\
Draft $(D)$ & $\mathrm{m}$ & $0 \cdot 1$ & $0 \cdot 09$ \\
Draft ratio & - & $0 \cdot 09$ & $0 \cdot 11$ \\
Branching complexity & - & 6 & 22 \\
Volume $\left(V_{\text {log }}\right)$ & $\mathrm{m}^{3}$ & $0 \cdot 11$ & $0 \cdot 5$ \\
Blockage & - & $0 \cdot 01$ & $0 \cdot 02$ \\
Weight & $\mathrm{N}$ & 8 & 27 \\
Vertical force ratio & - & $1 \cdot 1$ & $0 \cdot 2$ \\
Momentum & $\mathrm{kg} \mathrm{m} / \mathrm{s}$ & 10 & 29 \\
Wetted width & $\mathrm{m}$ & 24 & 15 \\
Mean depth in channel & $\mathrm{m}$ & $1 \cdot 3$ & $0 \cdot 6$ \\
Water velocity $(U)$ & $\mathrm{m} / \mathrm{s}$ & 1.4 & $0 \cdot 4$ \\
Unit stream power $(\omega)$ & $\mathrm{N} / \mathrm{m} \mathrm{s}$ & 125 & 113 \\
Energy grade slope & $\mathrm{m} / \mathrm{m}$ & $0 \cdot 008$ & $0 \cdot 009$ \\
Effective stream width & $\mathrm{m}$ & $13 \cdot 4$ & $7 \cdot 6$ \\
\hline
\end{tabular}


Table III. Mean and standard deviation for hydraulic and geomorphic characteristics for each study site during peak discharges in fall 2007

\begin{tabular}{|c|c|c|c|c|c|c|}
\hline & $\begin{array}{l}\text { Mean } \\
\text { wetted } \\
\text { depth } \\
\text { (m) }\end{array}$ & $\begin{array}{c}\text { Water } \\
\text { velocity } \\
(\mathrm{m} / \mathrm{s})\end{array}$ & $\begin{array}{l}\text { Power } \\
\text { (N/m s) }\end{array}$ & $\begin{array}{c}\text { Bed } \\
\text { slope } \\
(\mathrm{m} / \mathrm{m})\end{array}$ & $\begin{array}{l}\text { Bankfull } \\
\text { width } \\
\text { (m) }\end{array}$ & $\begin{array}{c}\text { Peak discharge } \\
\left(\mathrm{m}^{3} / \mathrm{s}\right)\end{array}$ \\
\hline Beaver River & 1.660 .30 & $0.860 \cdot 32$ & 1535 & 0.0010 .002 & $16 \cdot 03 \cdot 0$ & $21 \cdot 7$ \\
\hline French River & 0.740 .17 & $1.530 \cdot 34$ & 11984 & 0.0200 .010 & $11 \cdot 32 \cdot 5$ & $12 \cdot 0$ \\
\hline Knife River & 1.510 .29 & $1.440 \cdot 22$ & 13757 & 0.0060 .003 & $24 \cdot 45 \cdot 3$ & $54 \cdot 7$ \\
\hline Lt. East Knife & 1.480 .22 & $1 \cdot 170.42$ & 78135 & 0.0040 .015 & 3.40 .9 & 7 \\
\hline Lt. West Knife & 0.530 .15 & $1 \cdot 150 \cdot 33$ & 4036 & 0.0120 .013 & $3.70 \cdot 8$ & $2 \cdot 1$ \\
\hline Sucker River & 0.980 .13 & 1.840 .33 & 252169 & 0.0160 .008 & $9.92 \cdot 2$ & $17 \cdot 5$ \\
\hline Talmadge Creek & 0.780 .14 & 1.620 .25 & 247135 & 0.0250 .035 & $5 \cdot 31.6$ & $7 \cdot 0$ \\
\hline Upper Knife & 0.840 .08 & $1.480 \cdot 25$ & 9346 & 0.0090 .003 & $6 \cdot 61 \cdot 1$ & $8 \cdot 3$ \\
\hline W Split Rock & 2.480 .28 & 1.920 .45 & 153108 & 0.0070 .002 & 6.90 .9 & $54 \cdot 4$ \\
\hline a Brule River & 2.270 .61 & $2 \cdot 200 \cdot 61$ & 515439 & 0.0120 .008 & $22 \cdot 23 \cdot 3$ & $104 \cdot 0$ \\
\hline${ }^{\mathrm{a}}$ East Beaver & $1.200 \cdot 26$ & $1 \cdot 140 \cdot 35$ & 9176 & 0.0080 .005 & $11 \cdot 73 \cdot 2$ & $16 \cdot 3$ \\
\hline a Poplar River & 1.820 .33 & 3.070 .55 & 1111432 & 0.0340 .010 & $10 \cdot 92 \cdot 4$ & $62 \cdot 3$ \\
\hline
\end{tabular}

Depth, velocity and power values do not include water in the floodplain. a 2008 bracing study only.

diameter was $0.15 \mathrm{~m}(0.13 \mathrm{~m})$, and mean wood density was $0.74 \mathrm{~g} / \mathrm{cm}^{3}\left(0.33 \mathrm{~g} / \mathrm{cm}^{3}\right)$. The mean wetted width of the streams was $24 \mathrm{~m}(15 \mathrm{~m})$, and mean water depth in the channels was $1.3 \mathrm{~m}(0.6 \mathrm{~m})$. The mean water velocity in the channels was $1.4 \mathrm{~m} / \mathrm{s}(0.6 \mathrm{~m} / \mathrm{s})$, and unit stream power in the channels averaged $125 \mathrm{~N} / \mathrm{m} \mathrm{s}(113 \mathrm{~N} / \mathrm{m} \mathrm{s})$. Many characteristics appeared to follow a chi-square distribution (Merten, 2009), which is an acceptable distribution for multiple logistic regression analyses (Weisberg, 1985). The study streams varied within and among themselves in geomorphic and hydraulic characteristics; mean bed slopes ranged from 0.001 to $0.025 \mathrm{~m} / \mathrm{m}$ and peak discharges ranged from $2 \cdot 1$ to $54.7 \mathrm{~m}^{3} / \mathrm{s}$ (Table III).

Of the 344 wood pieces that met the criteria for this study, $110(32 \%)$ were entrapped before leaving the study reach; the mean length and diameter for entrapped pieces was 3.42 and $0.19 \mathrm{~m}$, whereas the mean length and diameter for non-entrapped pieces was 2.51 and $0.13 \mathrm{~m}$. Mean wood density was 0.81 and $0.71 \mathrm{~g} / \mathrm{cm}^{3}$ for entrapped and non-entrapped pieces.

The final model for entrapment was highly significant $(p<0.001)$ and included four predictor variables (Table IV). Nagelkerke's $r^{2}$ for the final model was 0.25 , corresponding to a Goodman-Kruskal gamma of 0.50 and Kendall's tau-a of $0 \cdot 22$. The four predictor variables were the length ratio, weight, branching complexity and rootwad presence. However, the individual $p$-values for branching complexity and rootwad presence were $>0.05$, and rootwad presence would have been excluded from the final model if the AIC penalty were increased from 2 to 3 .

Using the multiple logistic regression results, the probability $(P)$ of entrapment was calculated for each predictor as

$$
P_{\text {ent }}=\exp \left(\beta_{0}+\beta_{1} x_{1}\right) /\left(1+\exp \left(\beta_{0}+\beta_{1} x_{1}\right)\right)
$$

where $\beta_{0}$ was the intercept (e.g. -1.783 in Table IV), $\beta_{1}$ was the model coefficient for the variable of interest, and
Table IV. Variables retained in the final model for entrapment; $n=344$ pieces of wood (110 entrapped)

\begin{tabular}{lrrrrc}
\hline & Coefficient & SE & Wald Z & $p$-value & VIF \\
\hline Intercept & -1.783 & 0.214 & -8.34 & $<0.001$ & - \\
Length ratio & 2.959 & 0.618 & 4.79 & $<0.001$ & 1.205 \\
Weight & 0.044 & 0.018 & 2.41 & 0.0158 & 1.169 \\
Branching & -0.011 & 0.007 & -1.72 & 0.0846 & 1.230 \\
$\quad$ complexity & & & & & \\
Rootwad & -0.805 & 0.573 & -1.41 & 0.1599 & 1.034 \\
\hline
\end{tabular}

Overall model $p<0.001$ and Nagelkerke's $r^{2}=0.25$.

$x_{1}$ was the value for the variable of interest, with all other variables held constant. Using the model coefficient for the length ratio (2.959 in Table IV), Equation (5) indicated that a piece with the mean length ratio $\left(x_{1}=0 \cdot 31\right)$ had a 0.30 probability of being entrapped, whereas an increase to one standard deviation above the mean $\left(x_{1}=\right.$ $0.67)$ was associated with a 0.55 probability of entrapment. Taking the difference $(0.55-0 \cdot 30=0.25)$ indicated that a piece with the higher length ratio was $25 \%$ more likely to be entrapped, assuming that all other variables were held constant. Similarly, increasing the weight of a piece from the mean value (8) to one standard deviation above the mean (35) was associated with a $15 \%$ increase in the probability of entrapment (Figure 4). Branching complexity and rootwad presence had weaker effects on entrapment. Decreasing the branching complexity from 6 (the mean value) to 1 (no branches, the least value) was associated with a $1 \%$ increase in the probability of entrapment, and the probability of entrapment was only $7 \%$ lower if a rootwad was present.

Expanding Equation (5) to consider changes in the full set of predictor variables yields

$$
\begin{aligned}
& P_{\text {ent }}=\exp \left(\beta_{0}+\beta_{1} x_{1}+\beta_{2} x_{2}+\beta_{3} x_{3}+\beta_{4} x_{4}\right) / \\
& \left(1+\exp \left(\beta_{0}+\beta_{1} x_{1}+\beta_{2} x_{2}+\beta_{3} x_{3}+\beta_{4} x_{4}\right)\right)
\end{aligned}
$$



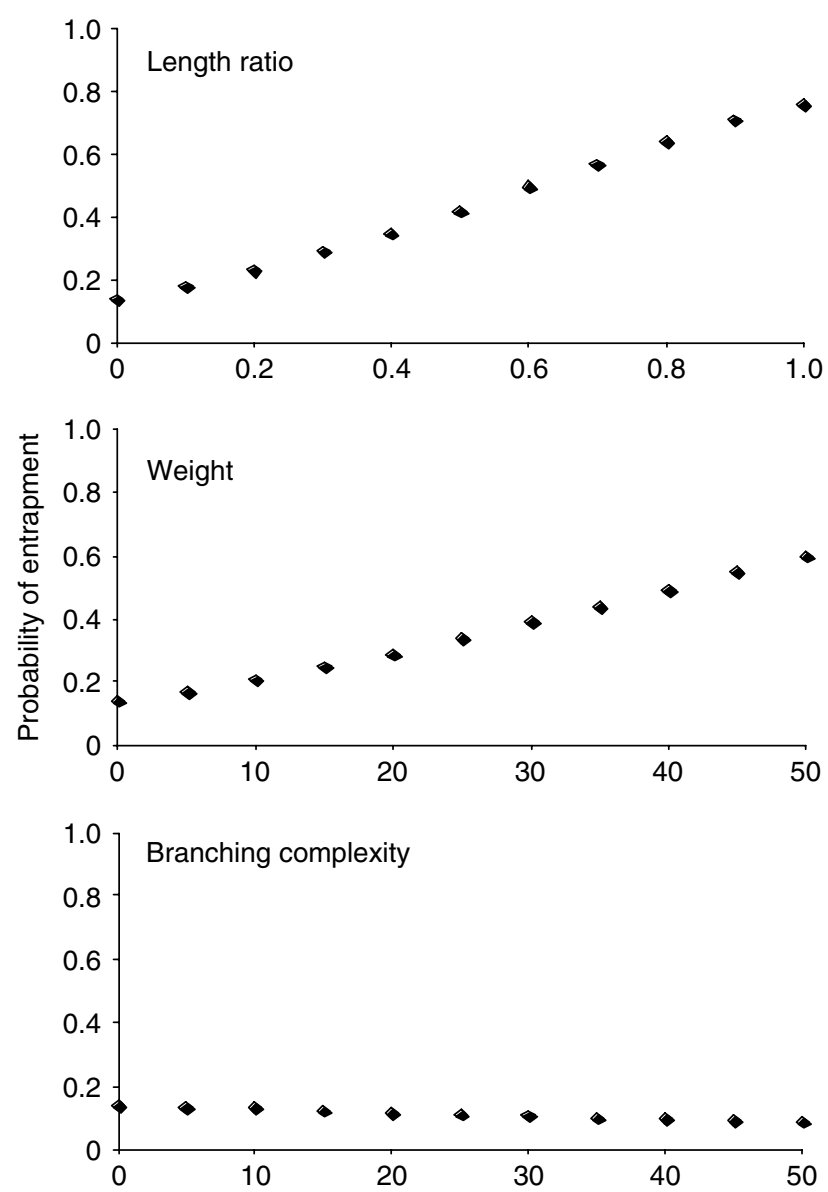

Figure 4. Expected probability of entrapment as a function of the length ratio, weight or branching complexity

where $\beta_{1} x_{1} \ldots \beta_{4} x_{4}$ correspond to coefficients and values for the four predictor variables. Combining the prior examples, a piece of wood with length ratio of $0 \cdot 31$, weight of 8 , branching complexity of 6 and a rootwad had a probability of entrapment $P_{\text {ent }}=0 \cdot 20$. Conversely, a piece with length ratio of $0 \cdot 67$, weight of 35 , branching complexity of 1 and no rootwad had $P_{\text {ent }}=0 \cdot 85$.

A total of 166 new pieces were entrapped in 2008 (Figure 5). The most common method of entrapment was pieces that were lying loose in the channel $(n=72)$, followed by pieces that were braced by other pieces of wood in the channel ( $n=48)$, ejected onto the floodplain ( $n=18)$, braced by rocks in the channel $(n=14)$, braced by the stream banks or bed $(n=9)$ and braced by live vegetation (primarily trees) in the channel $(n=5)$.

\section{DISCUSSION}

We found two factors to be of primary importance for wood entrapment in natural streams: the ratio of piece length to effective stream width (length ratio) and piece weight. The coefficient of determination for the entrapment model, while not high (i.e. 0.25), was higher than obtained in other studies (e.g. 0.01 by Jacobsen et al. (1999) and 0.06 by Braudrick and Grant (2001)). The reason may be that we evaluated a diverse set of conditions. Our study included a natural range of wood pieces, geomorphology and hydraulics from nine streams, providing the entrapment model with much variability to explain. Although a higher coefficient of determination was obtained using a dense network of obstructions in a flume (Bocchiola et al., 2006), the applicability of those results to natural conditions is unclear.

Pieces with higher length ratios were more likely to be entrapped, according to our multiple logistic regression model. Previous studies have also determined that the ratio of piece length to stream width was of primary importance for entrapment (Lienkaemper and Swanson, 1987; Gurnell et al., 2002; Hassan et al., 2005; Wyzga and Zawiejska, 2005). However, those studies used bankfull channel width as the measure of stream width rather than effective stream width, which takes into account both the actual wetted width and the infringement of woody vegetation. Our length ratio also influenced mobilization, where stationary pieces with greater length ratios were less likely to be mobilized (Merten et al., 2010).

Weight was also important in the final model for entrapment; heavier pieces were more likely to be entrapped. Piece weight is the product of volume and

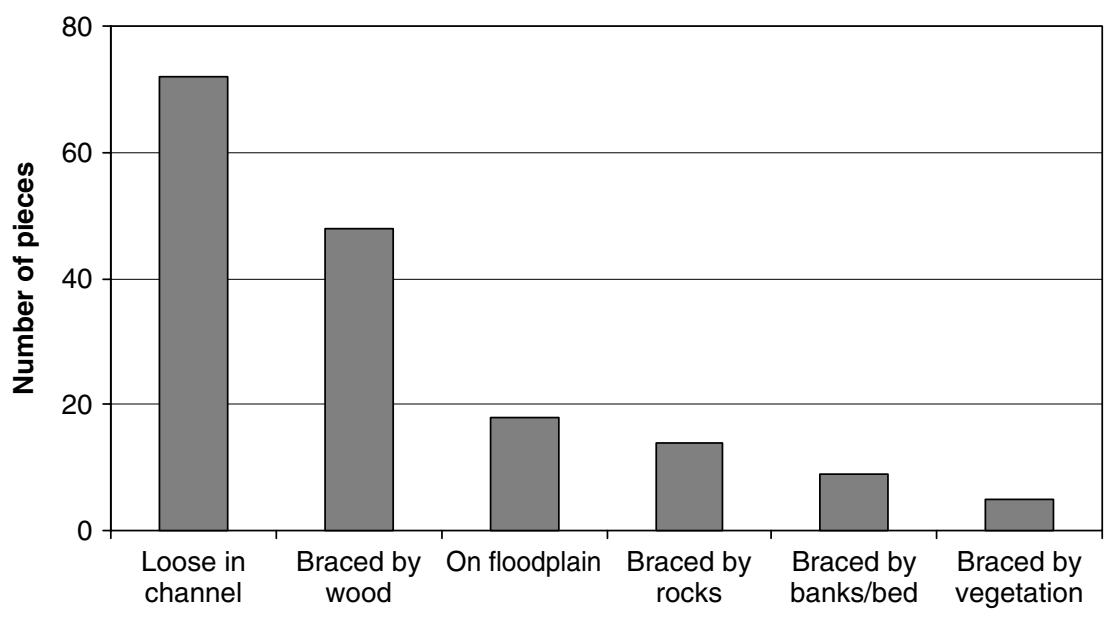

Figure 5. Numbers of new pieces found in 2008 in three stream reaches, according to location or manner in which pieces were braced 
density, which suggests two possible explanations for the positive association of weight with entrapment. Greater volume may increase the probability that a piece will contact obstructions, including submerged obstructions as discussed previously (e.g. large boulders, islands or other pieces of wood) or above-water obstructions such as tree roots and low-hanging branches. Higher piece density increases draft, and thus the likelihood that the piece will contact the stream bed. Weight may therefore relate to the same mechanisms as draft ratio and blockage (i.e. entrapment from contact with obstructions or the stream bed) and is itself a component of momentum.

Branching complexity and rootwad presence were also included in the final model for entrapment. Contrary to our expectations, pieces with higher branching complexity and rootwads were less likely to be entrapped. An unknown mechanism may be at work with branching complexity and rootwad presence, or the variables may be correlated with some unmeasured parameter that decreased the likelihood of entrapment. However, the statistical significance of both variables was weak (the individual $p$-values for both variables were $>0.05$ ) and the predictors may not be meaningful. Branching complexity is influenced by the number of small twigs (Newbrey et al., 2005), which are unlikely to play a role in entrapment. Small twigs break off if, for example, they become caught between rocks and are unable to resist the hydrodynamic drag acting on the full piece. Future studies might instead consider a branching ratio, such as the combined length of large branches $(>0.05 \mathrm{~m}$ in diameter, excluding the main bole of the piece) divided by the length of the main bole.

The final model did not include draft ratio, momentum or blockage. Although previous studies have suggested that draft ratio influences entrapment (Braudrick and Grant, 2001; Haga et al., 2002), those studies minimized the influence of the length ratio by using pieces that were shorter than the channel width. Our dataset was much more diverse in terms of length ratio, piece weight, branching complexity and rootwad presence (Braudrick and Grant, 2001; Haga et al., 2002) and covered a natural range of conditions.

The final model Equation (5) can be applied to a range of conditions, as outlined in Table III. Although the current study included only a single year, the study streams exhibited a range of geomorphic and hydraulic conditions; thus, the final model is likely applicable to at least a similar range of conditions in other streams. The peak discharges for the study period varied from $2 \cdot 1$ to $54.7 \mathrm{~m}^{3} / \mathrm{s}$ at the nine study streams, corresponding to a range of mean wetted widths from 3.8 to $71.2 \mathrm{~m}$. Lengths of pieces were from 1.0 to $15.3 \mathrm{~m}$ with estimated weights from 0.08 to $327 \mathrm{~N}$. Our analyses are thus applicable to natural pieces and streams that are of interest to stream managers.

Our study can inform management of wood in streams. For example, the model (Equation 5) could be used to determine the effective stream width required to reduce wood entrapment around road crossings or other infrastructure, provided that data were collected on wood characteristics. The requisite stream width, in particular, could be used to design bridge spans or culvert diameters. We noted that a pair of culverts in one study reach entrapped a disproportionate number of pieces, including 42 marked pieces (that were excluded from analyses). Using a mean piece length of $2.8 \mathrm{~m}$, our model equation associates a $33 \%$ reduction in the entrapment by replacing a 3-m culvert with a 6-m span bridge.

Alternatively, our study may also be applied to promote wood entrapment in managed or restored streams where wood is valued for its ecological functions. The model Equation (5) can be used to determine the effective stream width required to entrap pieces of a given length. The model can also be used for a given stream width to determine the length of pieces required to become entrapped. If natural wood pieces of the required size are not available, short-term wood additions and long-term riparian management may be used to increase present and future standing stocks of instream wood (Murphy and Koski, 1989; Czarnomski et al., 2008).

Regardless of input levels, entrapment of wood in streams begets more wood in streams (Abbe and Montgomery, 2003; Bocchiola et al., 2008; Warren and Kraft, 2008). Of the new pieces of wood that were entrapped in 2008, more pieces were entrapped by other pieces of wood than were ejected onto the floodplain or entrapped by rocks, stream banks or vegetation. No spanning logjams were present in 2008; scattered pieces of wood provide valuable ecological functions and a positive feedback toward further wood accumulation even without the influence of spanning logjams. Pre-existing wood may be most effective at entrapment due to irregular shapes (presenting more opportunities than rocks for wedging) that can contact pieces floating at a variety of elevations. In addition, more complex processes (e.g. three-dimensional flow patterns) that led pre-existing pieces to be deposited may remain in effect.

In conclusion, entrapment remains difficult to predict in natural streams. Although the model derived in this study explained more variability in entrapment than previous field studies, the coefficient of determination was only $0 \cdot 25$. Of the new pieces entrapped in 2008, $43 \%$ were lying loose in the channel and not entrapped by any obvious obstruction. In some cases, entrapment may simply occur wherever the piece is located when high water recedes (Jacobsen et al., 1999), particularly in systems where length and draft ratios are low and obstructions are sparse. The process of wood entrapment merits further study for predicting the ecological functions of wood and the success of restoration efforts.

\section{ACKNOWLEDGEMENTS}

Wood and survey data were collected by Jo Fritz, Ryan Carlson, Dustin Wilman, Nicole Rath, Levi Drevlow, Ryan Johnsen and April Bebault. Rachael Stanze and Nathan Schroeder collected continuous discharge data 
from six streams. Logistical support was provided by Tracy Close of Minnesota Department of Natural Resources, Marty Rye of USDA Forest Service, the Minnesota Cooperative Fish and Wildlife Research Unit and the Natural Resources Research Institute. Mention of trade names or commercial products does not imply endorsement by the US Government. Funding was provided by the Minnesota Department of Natural Resources and Minnesota Sea Grant. The Minnesota Cooperative Fish and Wildlife Research Unit is jointly sponsored by the US Geological Survey, the University of Minnesota, the Minnesota Department of Natural Resources, the Wildlife Management Institute and the US Fish and Wildlife Service.

\section{REFERENCES}

Abbe TB, Montgomery DR. 2003. Patterns and processes of wood debris accumulation in the Queets river basin, Washington. Geomorphology 51: $81-107$.

Angermeier PL, Karr JR. 1984. Relationships between woody debris and fish habitat in a small warmwater stream. Transactions of the American Fisheries Society 113: 716-726.

Arcement GJ, Schneider VR. 1989. Guide for selecting Manning's roughness coefficients for natural channels and flood plains. U.S. Geological Survey Water-Supply Paper 2339.

Beechie TJ, Sibley TH. 1997. Relationships between channel characteristics, woody debris, and fish habitat in northwestern Washington streams. Transactions of the American Fisheries Society 126: 217-229.

Berg N, Carlson A, Azuma D. 1998. Function and dynamics of woody debris in stream reaches in the central Sierra Nevada, California. Canadian Journal of Fisheries and Aquatic Sciences 55: 1807-1820.

Bilby RE. 1984. Removal of woody debris may affect stream channel stability. Journal of Forestry 82: 609-613.

Bocchiola D, Rulli MC, Rosso R. 2006. Transport of large woody debris in the presence of obstacles. Geomorphology 76: 166-178.

Bocchiola D, Rulli MC, Rosso R. 2008. A flume experiment on the formation of wood jams in rivers. Water Resources Research 44: 1-17.

Braudrick CA, Grant GE. 2001. Transport and deposition of large woody debris in streams: a flume experiment. Geomorphology 41: 263-283.

Braudrick CA, Grant GE, Ishikawa Y, Ikeda H. 1997. Dynamics of wood transport in streams: a flume experiment. Earth Surface Processes and Landforms 22: 669-683.

Brooks AP, Abbe T, Cohen T, Marsh N, Mika S, Boulton A, Broderick T, Borg D, Rutherfurd I. 2006. Design Guidelines for the Reintroduction of Wood into Australian Streams, Land and Water Australia: Canberra.

Burnham KP, Anderson DR. 1998. Model Selection and Inference: A Practical Information-theoretic Approach, Springer: New York, NY.

Czarnomski NM, Dreher DM, Snyder KU, Jones JA, Swanson FJ. 2008. Dynamics of wood in stream networks of the western Cascades Range, Oregon. Canadian Journal of Forest Research 38: 2236-2248.

Detenbeck NE, Brady VJ, Taylor DL, Snarski VM, Batterman SL. 2005. Relationship of stream flow regime in the western Lake Superior basin to watershed type characteristics. Journal of Hydrology 309: 258-276.

Eggert SL, Wallace JB. 2007. Wood biofilm as a food resource for stream detritivores. Limnology and Oceanography 52: 1239-1245.

Flebbe PA, Dolloff CA. 1995. Trout use of woody debris and habitat in Appalachian wilderness streams of North Carolina. North American Journal of Fisheries Management 15: 579-590.

Golladay SW, Battle JM, Palik BJ. 2007. Large wood debris recruitment on differing riparian landforms along a gulf coastal plain (USA) stream: a comparison of large floods and average flows. River Research and Applications 23: 391-405.

Gordon ND, McMahon TA, Finlayson BL, Gippel CJ, Nathan RJ. 2004. Stream Hydrology: An Introduction for Ecologists, John Wiley and Sons: New York, NY.

Gregory SV, Boyer KL, Gurnell AM. 2003. The Ecology and Management of Wood in World Rivers, American Fisheries Society: Bethesda, MD.
Gurnell AM, Piegay H, Swanson FJ, Gregory SV. 2002. Large wood and fluvial processes. Freshwater Biology 47: 601-619.

Haga H, Kumagai T, Otsuki K, Ogawa S. 2002. Transport and retention of coarse woody debris in mountain streams: an in situ field experiment of log transport and a field survey of coarse woody debris distribution. Water Resources Research 38: 1-16.

Harrelson CC, Rawlins CL, Potyondy JP. 1994. Stream channel reference sites: an illustrated guide to field technique. U.S.D.A. Forest Service General Technical Report RM-245, Fort Collins, CO.

Hassan MA, Hogan DL, Bird SA, May CL, Gomi T, Campbell D. 2005. Spatial and temporal dynamics of wood in headwater streams of the Pacific Northwest. Journal of the American Water Resources Association 41: 899-919.

Jacobsen PJ, Jacobsen KM, Angermeier PL, Cherry DS. 1999. Transport, retention, and ecological significance of woody debris within a large ephemeral river. Journal of the North American Benthological Society 18: $429-444$.

Johnson LB, Breneman DH, Richards C. 2003. Macroinvertebrate community structure and function associated with large wood in low gradient streams. River Research and Applications 19: 199-218.

Kreutzweiser DP, Good KP, Sutton TM. 2005. Large woody debris characteristics and contributions to pool formation in forest streams of the Boreal shield. Canadian Journal of Forest Research 35: 1213-1223.

Latterell JJ, Naiman RJ. 2007. Sources and dynamics of large logs in a temperate floodplain river. Ecological Applications 17: 1127-1141.

Lienkaemper GW, Swanson FJ. 1987. Dynamics of large woody debris in old-growth Douglas-fir forests. Canadian Journal of Forest Research 17: $150-156$.

Mao L, Andreoli A, Comiti F, Lenzi MA. 2008. Geomorphic effects of large wood jams on a Sub-Antarctic mountain stream. River Research and Applications 24: 249-266.

Merten EC. 2009. Instream wood transport, and effects of forest harvest on geomorphology and fish, in northern Minnesota streams. PhD dissertation, University of Minnesota-Twin Cities, Minneapolis, MN.

Merten EC, Decker-Fritz JA. 2010. Standing stocks of large wood in twelve tributary streams along the north shore of Lake Superior. Journal of Freshwater Ecology 25: 159-161.

Merten EC, Finlay J, Johnson L, Newman R, Stefan H, Vondracek B. 2010. Factors influencing wood mobilization in streams. Water Resources Research (in press). DOI: 10.1029/2009WR008772.

Millington CE, Sear DA. 2007. Impacts of river restoration on smallwood dynamics in a low-gradient headwater stream. Earth Surface Processes and Landforms 32: 1204-1218.

Murphy ML, Koski KV. 1989. Input and depletion of woody debris in Alaska stream and implications for streamside management. North American Journal of Fisheries Management 9: 427-436.

Mutz M, Rohde A. 2003. Processes in surface-subsurface water exchange in a low energy sand-bed stream. International Review of Hydrobiology 88: $290-303$.

Nagelkerke NJ. 1991. A note on the general definition of the coefficient of determination. Biometrika 78: 691-692.

Newbrey MG, Bozek MA, Jennings MJ, Cook JE. 2005. Branching complexity and morphological characteristics of coarse woody structure as lacustrine fish habitat. Canadian Journal of Fisheries and Aquatic Sciences 62: 2110-2123.

Opperman JJ, Merenlender AM. 2007. Living trees provide stable large wood in streams. Earth Surface Processes and Landforms 32: 1229-1238.

Stofleth JM, Shields FD, Fox GA. 2008. Hyporheic and total transient storage in small, sand-bed streams. Hydrological Processes 22: 1885-1984.

Walter RC, Merritts DJ. 2008. Natural streams and the legacy of waterpowered mills. Science 319: 299-304.

Warren DR, Kraft CE. 2008. Dynamics of large wood in an eastern U.S. mountain stream. Forest Ecology and Management 256: 808-814.

Weisberg S. 1985. Applied Linear Regression, Wiley: New York, NY.

Wohl E, Goode JR. 2008. Wood dynamics in headwater streams of the Colorado Rocky Mountains. Water Resources Research 44: 1-14.

Wyzga B, Zawiejska J. 2005. Wood storage in a wide mountain river: case study of the Czarny Dunajec, Polish Carpathians. Earth Surface Processes and Landforms 30: 1475-1494. 